discomyces madurae (Vincent) which was investigated by the Pasteur Institute, Tunis, and pronounced to be aspergillus (sterigmatocystis) nidulans. A description of the histopatholog. is not given. They considered that possibly aspergillus (sterigmatocystis) nidulans, or some closely allied fungus may be the pathogenic agent in mycetomata not due to discomyces. This may be so, but there are other workers in this field who consider that aspergillus may be a secondary implantation on a primary discomycotic condition. In very many articles dealing with aspergillosis, A. fumigatus is incriminated; sometimes apparently without very much reason, as diagnostic chäracters are not given. Even if they were, it would perhaps be difficult to place such fungi as the characters of the group have been insufficiently worked out. It is certain, however, from the literature that fungi of the genus aspergillus are responsible for both saphrophytic and parasitic invasions of man and animals and that they may cause not only surface infections but definite granulomata. There can be no doubt from the histopathology of the granulomata in $m y$ cases that the aspergillus was a true parasite and almost certainly acting primarily. In the second case there was no evidence whatever that there were organisms of any other sort present in the tissue. In the first case there were bacilli and cocci, but they were in all probability those of a secondary infection.

My thanks are due to Mr. H. Hawley of the King Institute of Preventive Medicine, Guindy, for the microphotographs, and to the South Indian Branch of the British Medical Association for meeting the expenditure associated with the animal experiments.

\title{
THREE CASES OF EMBOLISM OF A RETINAL ARTERY
}

BY

\section{T. HARRISON BUtLER}

BIRMINGHAM

C.J.W., male, aged 21 years, came to the Birmingham Eye Hospital on December $\tau, 1926$, and was examined at 10 a.m. He stated that at 7.40 a.m. the vision of the left eye suddenly failed and that for some time he had not the slightest perception of light. In about half an hour he began to see again, but even now the sight is not normal. He suffers from morbus cordis.

The vision of each eye is $6 / 6$. There is a quadrantic notch in the field of vision involving the lower temporal aspect, as shown in the chart. 
The superior artery is full of blood as far as the first fork. From here on the two branches are completely empty for about onequarter disc diameter; beyond this area the blood column is segmented. When the globe is pressed with the finger there is pulsation as far as the first fork of the artery but not beyond. The superior nasal vein has a white filmy sheath, the so-called "peri-

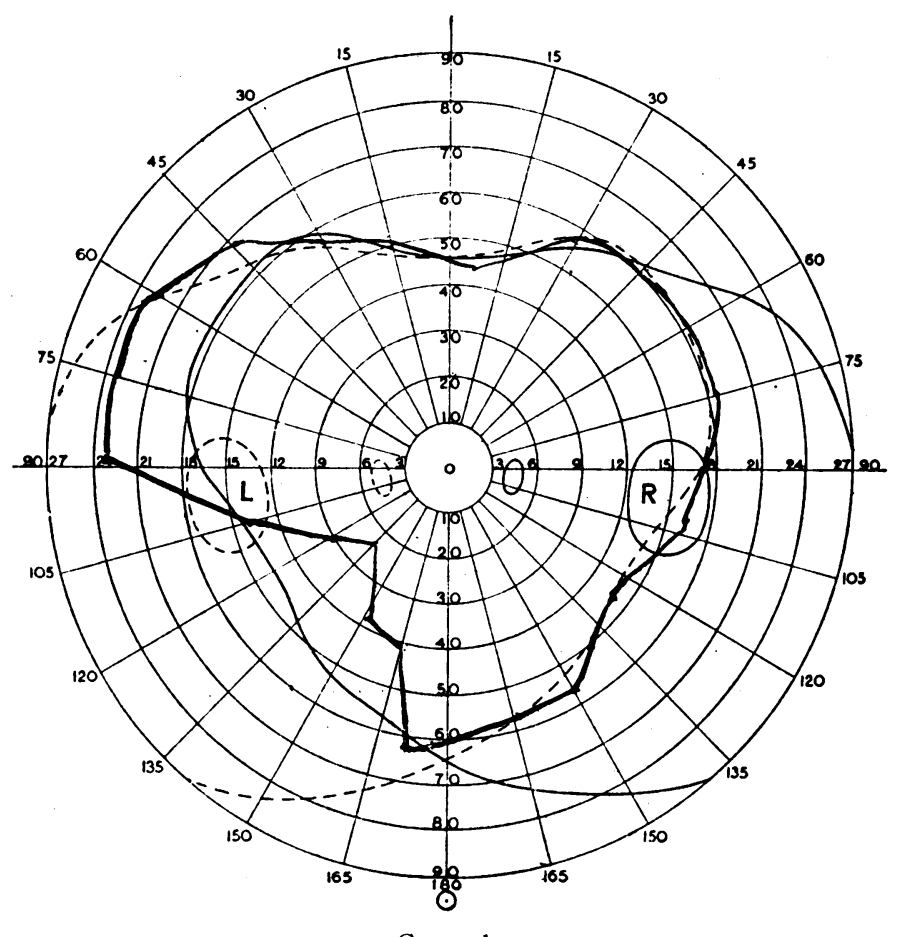

CASE 1.

phlebitis." There is some general retinal oedema especially in the macular region, but there is no definite cherry spot.

The patient was at once admitted and paracentesis was performed with a Ziegler knife and the eye gently massaged. A capsule of amyl nitrite was administered. Five hours later the patient was shown to the Midland Ophthalmological Society. An astonishing change had taken place. The previously empty artery was now full and the segmentation had disappeased. Careful search revealed another block in the circulation far away in the periphery of the field. Here the appearance was exactly similar to that seen at the site of the original obstruction. Four days later this obstruction could no longer be seen and the patient was discharged. 
Vision was $6 / 6$ and no change had taken place in the field which still showed the quadrantic defect. This was present unchanged on December 17.

The sequence of events is obvious. At first a complete obstruction of the central retinal artery was present. The embolus passed on to the site where we first saw it, and finally forced its way to a peripheral fork. The appearance when first examined is shown

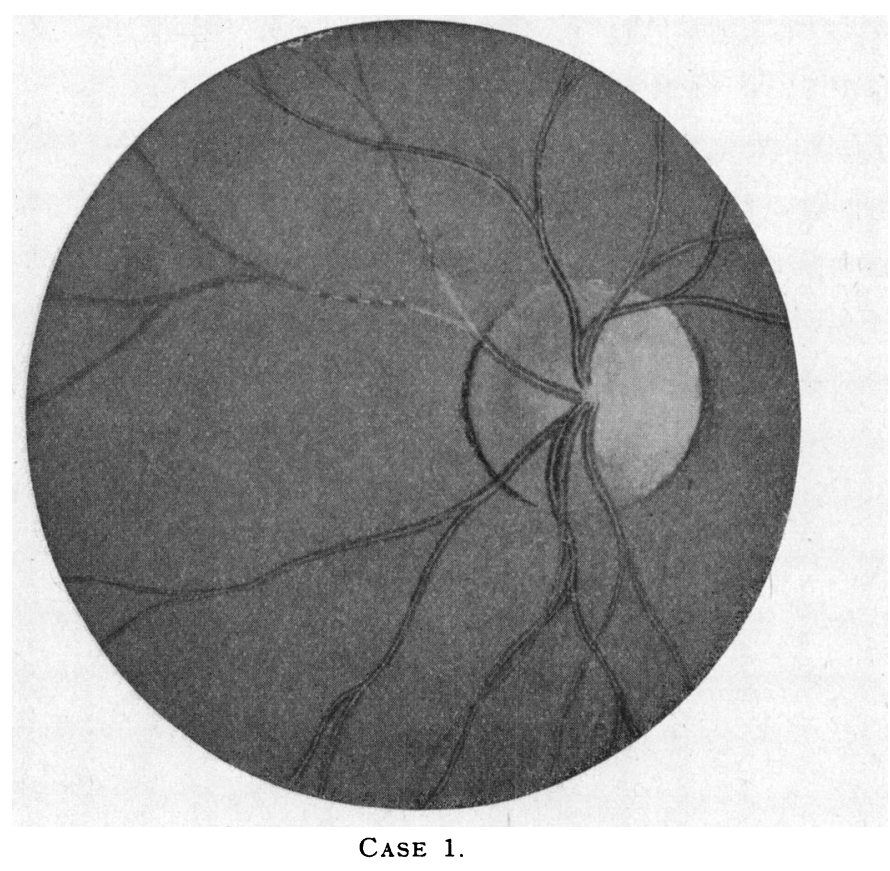

in the drawing of the fundus which was elaborated from a rough sketch made at the time. At the end of January the condition is unchanged. The patient has normal central acuity but is still conscious of the defect in the field which will probably be permanent.

\section{Case 2}

T.J.D., male, aged 31 years, came to the Birmingham Eye Hospital, February 15, 1927. He stated that at 10 p.m., on February 14, he felt giddy and the sight of the left eye suddenly went.

On examination it was found that the vision of the left eye was reduced to perception of movement on the temporal side only. 
Ophthalmoscopic examination showed that the whole retina was oedematous with the exception of a triangular area extending from the vertical diameter of the disc as a base to a spot near the macula as the apex. There was a well-marked cherry spot at the actual macula. The normal retinal area was fed by a cilio-retinal artery. The arteries were not obviously small and there was no evidence of segmentation of the blood column. The patient was admitted

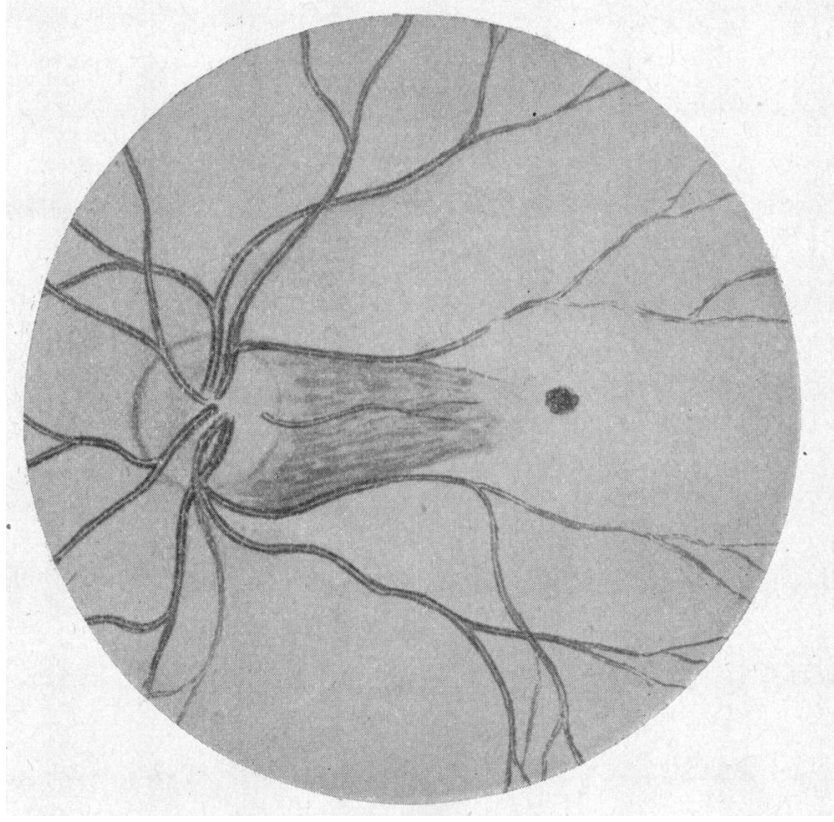

CASE 2.

and paracentesis of the anterior chamber was performed. He was given a capsule of amyl nitrite to smell.

On February 22 the contrast between the normal and the oedematous retina was more obvious, there was more oedema. There was a retinal haemorrhage from the artery bounding the lower side of the normal retinal triangle. March 26: the retina is now normal in appearance with the exception of some white dots in the area fed by the cilio-retinal artery. The vision is not improved and the disc is becoming atrophic. Examination of the heart revealed the presence of a soft blowing systolic murmur at the apex.

The appearance of the retina when first examined is shown in the drawing. 


\section{Case 3}

This case was a private patient and was interesting in that the embolism produced a sharply-defined altitudinal macular hemianopsia.

Mrs. A. H. C., aged 60 years, complains that yesterday she suddenly noted a blur over the right eye and that now the upper half of the field of vision is blind. Two years ago she suffered from a painful thrombosis of a varicose vein in the left leg.

$\mathrm{V} . \mathrm{R} .=6 / 18 ; \mathrm{V} . \mathrm{L} .=6 / 12$.

Blood pressure, 180 systolic.

The peripheral field of vision is normal and shows no trace of hemianopsia when tested with a $2 \mathrm{~mm}$. object on the Lister perimeter. The central field was mapped out on the Bjerrum screen. There is a total paracentral scotoma almost semicircular in outline. It is bounded below by the horizontal diameter of the chart and above it almost accurately fills the 15 degree circle.

There is a bright embolus just beyond the first fork of the inferior temporal artery blocking the branch to the macular region. The blood column in the artery distal to the embolus is segmented and motionless. There is no retinal oedema.

Nineteen days later the acuity of the right eye had sunk to $6 / 60$. The embolus was still visible. There was then segmentation of the blood column and the stream could be seen slowly moving on. Treatment was refused.

\section{A CASE OF MONOCULAR DIPLOPIA}

BY

\section{T. HARRISON BUtLER}

BIRMINGHAM

A. G., male, aged 54 years, came to the Coventry Hospital on August 16, 1927, complaining of double vision in the right eye.

He stated that thirty years ago a file which he was using hit the right eye and scratched the cornea. No trace of any opacity or corneal irregularity. was found.

The diplopia began ten years ago. Before this time he was a marksman in the Volunteers, and had perfect acuity in the right eye as far as he knew. Great difficulty was experienced in getting an accurate retinoscopy because there was a dark band across the pupil during the movement of the shadow.

With : $-1.0 \mathrm{D}$. sphere and $+4.0 \mathrm{D}$. cylinder axis $95^{\circ} \mathrm{V}:=6 / 60$. 